\title{
Imaging of High-Risk Plaque
}

\author{
Dmitry Nemirovsky \\ Cardiology Fellow, Mount Sinai Hospital, The Zena and Michael A. Weiner Cardiovascular Institute, \\ New York, N.Y., USA
}

Winner of the Karger/Clinical Cardiology Council, AHA Review Article Contest

\section{Key Words}

Vulnerable $\cdot$ Plaque $\cdot$ Imaging $\cdot$ Unstable $\cdot$ Coronary

\begin{abstract}
'High-risk' or 'vulnerable' plaques in the coronary arteries have characteristics that make them more prone to disruption and subsequent thrombosis - the mechanisms of most acute coronary syndromes (ACS). There are a number of imaging modalities that are capable of visualizing these features. This article discusses invasive modalities for identifying 'high-risk' plaque such as intravascular ultrasound, coronary angioscopy, optical coherence tomography, near-infrared spectroscopy and coronary thermography. It also discusses the use of noninvasive modalities such as computed tomography MRI and ultrasound. When these imaging modalities are combined with standard cardiac risk factors and more novel markers of systemic inflammation and thrombogenicity we can improve our ability to identify the 'high-risk' patient.
\end{abstract}

Copyright @ 2003 S. Karger AG, Base
During the past decade, we have understood that the atherosclerotic lesions that underlie the most threatening complications of coronary artery disease (CAD), i.e., unstable angina, myocardial infarction (MI), and sudden cardiac death, are not necessarily those that cause the greatest degree of stenosis of the lumen [1,2]. Rather, 'high-risk' or 'vulnerable plaques' have certain pathological characteristics that make them more prone to disruption and subsequent thrombosis - the mechanisms of most acute coronary syndromes (ACS). Our preventive approach to $\mathrm{CAD}$ has led us to recognize the high-risk patients and act to intervene by modifying the features that make them high risk. We now have a similar preventive mind-set in terms of our approach to coronary plaque. Our goal is to understand what characterizes a high-risk lesion to allow us to intervene either locally on the lesion or systemically on the high-risk patient plagued by the lesion.

\section{Pathogenesis of Atherosclerotic Plaque}

Fuster et al. [3] have described in detail the phases of atherogenesis (fig. 1). Phase 1 represents the progression from normal to a fatty streak, composed of foam cells (lipid-rich macrophages), smooth muscle cells, and extracel-

Dmitry Nemirovsky, MD

172 West 79th Street, Apt. 4E

New York, NY 10024 (USA)

Tel. +19179213858

E-Mail dmitry.nemirovsky@mssm.edu
Fax +41613061234

E-Mail karger@karger.ch www.karger.com (c) 2003 S. Karger AG, Basel

Accessible online at: www. karger.com/crd 


\begin{tabular}{|c|c|c|c|}
\hline $\begin{array}{l}\text { Plaque } \\
\text { progression }\end{array}$ & $\begin{array}{l}\text { American Heart } \\
\text { Association }\end{array}$ & $\begin{array}{l}\text { Lesion } \\
\text { morphology }\end{array}$ & $\begin{array}{l}\text { Clinical } \\
\text { symptoms }\end{array}$ \\
\hline \multirow{3}{*}{ Phase 1} & I (initial) & Foam cells & \multirow{5}{*}{ No symptoms } \\
\hline & II (fatty streaks) & $\begin{array}{l}\text { Foam cells, smooth muscle cells, and } \\
\text { extracellular lipid droplets }\end{array}$ & \\
\hline & III (intermediate) & $\begin{array}{l}\text { Smooth muscle cells surrounded by } \\
\text { extracellular connective tissue, } \\
\text { fibrils, and lipid deposits }\end{array}$ & \\
\hline \multirow[t]{2}{*}{ Phase 2} & IV (atheroma) & $\begin{array}{l}\text { Confluent cellular lesions with a great } \\
\text { deal of extracellular lipid, intermixed } \\
\text { with fibrous connective tissue }\end{array}$ & \\
\hline & Va (fibroatheroma) & $\begin{array}{l}\text { Extracellular lipid covered by thin } \\
\text { fibrous cap }\end{array}$ & \\
\hline Phase 3 & VI (complicated) & $\begin{array}{l}\text { Disruption of IV or Va lesion with a } \\
\text { mural thrombus which may of may not } \\
\text { occlude the artery }\end{array}$ & \\
\hline Phase 4 & VI & $\begin{array}{l}\text { Disruption of IV or Va lesion with an } \\
\text { occlusive thrombus }\end{array}$ & $\begin{array}{l}\text { Acute syndromes, myocardial } \\
\text { infarction, unstable angina, } \\
\text { ischemic sudden death }\end{array}$ \\
\hline Phase 5 & $\begin{array}{r}\mathrm{Vb} \text { (calcific) } \\
\text { Vc (fibrotic) }\end{array}$ & $\begin{array}{l}\text { Changes in geometry of the disrupted } \\
\text { plaque and organization or mural } \\
\text { thrombus by connective tissue may } \\
\text { lead to formation of occlusive and } \\
\text { fibrotic and/or calcific type }\end{array}$ & $\begin{array}{l}\text { Silent occlusive process or } \\
\text { angina pectoris }\end{array}$ \\
\hline
\end{tabular}

Fig. 1. Phases and lesion morphology of progression of coronary atherosclerosis according to gross pathological and clinical findings. Adapted from ref. 1.

lular lipid deposits, into an atheroma where these cells are intermixed with fibrous connective tissue. This is an inflammatory process triggered by subintimal uptake and oxidation of plasma low-density lipoprotein (LDL). Phase 2 involves the progression from atheroma to fibroatheroma, where the constituent cells become covered by a fibrous plaque. Although these lesions are usually asymptomatic and undetectable by angiography, they are responsible for the most ACS.

Plaque rupture or erosion initiates phase 3 or 4 . In phase 3 , a cycle of thrombosis, healing, and remodeling ensues, eventually leading to a stable stenotic lesion that can cause symptoms of stable angina. In phase 4 the disruption of the plaque leads to the formation of an occlusive thrombus, leading to unstable angina, MI, or sudden death. Phase 5 involves the formation of chronically occlusive and often clinically silent plaque.

\section{In Search of the 'High-Risk' Plaque}

Three histological aspects from postmortem studies have been correlated with progression of plaque into phase 4: the amount of lipid in the core of the plaque, the thinness of the fibrous cap, and the degree of inflammatory cell infiltrate [4]. A plaque with a lipid-rich necrotic core, a thin fibrous cap, and a large inflammatory cell infiltrate is most prone to disruption in the setting of mechanical stress or progressive inflammation [4, 5]. Virmani et al. [6] have shown that the mean necrotic core size is greatest in pathological specimens of ruptured plaques. Davies et al. [7] have estimated that when at least $40 \%$ of the total plaque area is composed of lipid, the atheroma is at risk of rupture. Stability of the core also relates to temperature. As the temperature increases, the core becomes softer and more likely to rupture [8].

The cap overlying the necrotic core consists of a collagen-rich matrix. The thinnest portion of the cap is at the shoulder region and appears to be most prone to rupture 


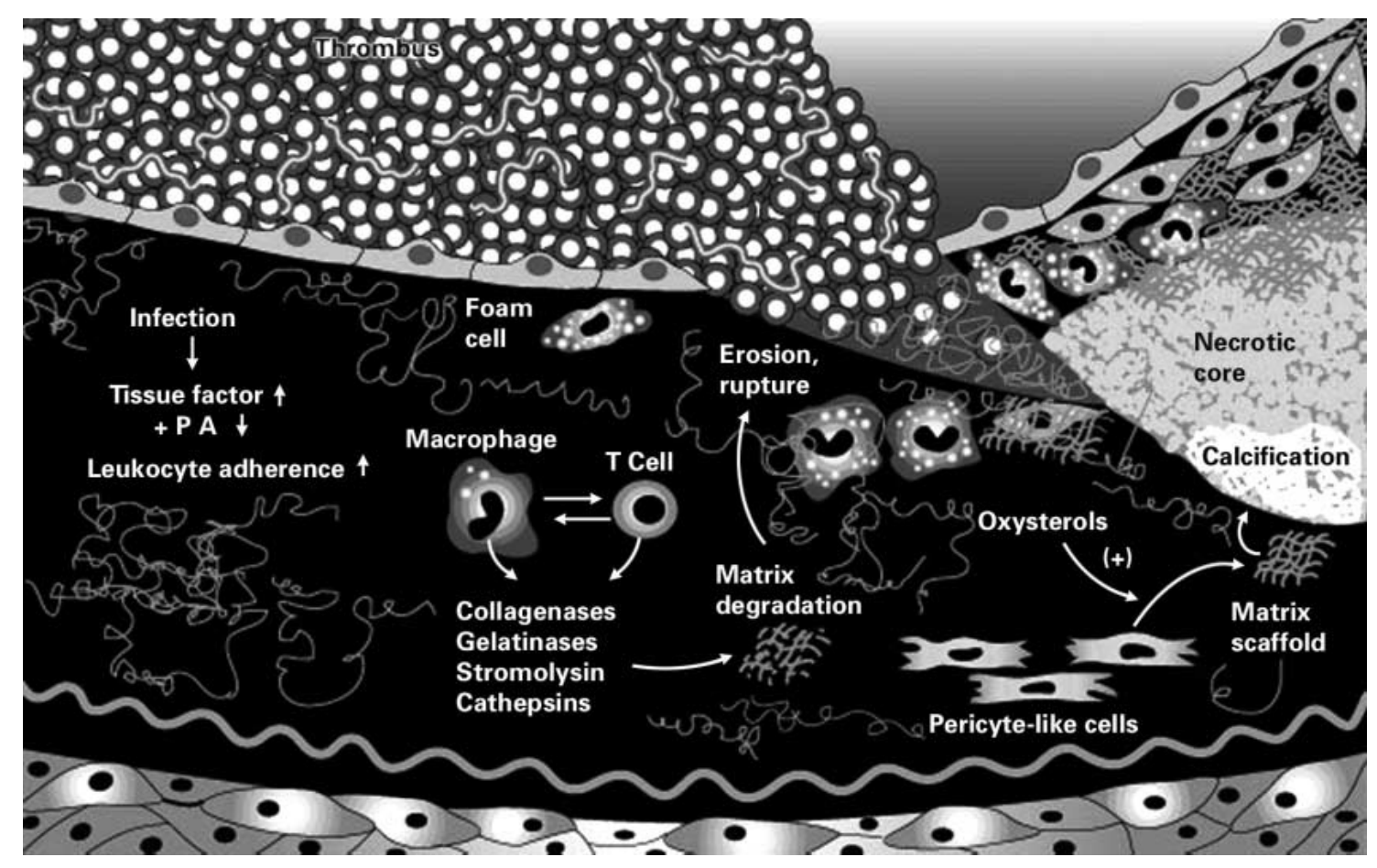

Fig. 2. [Adapted from Lusis AJ. Nature 2000;407:233-241.] Complex lesions and thrombosis. Proteinases in a vulnerable plaque degrade matrix. Systemic effects such as the induction of acute phase proteins may contribute to destabilizing plaques and promoting thrombosis.

[8] (fig. 2). Thin fibrous caps (usually measuring 65-150 $\mu \mathrm{m})$ have been found from autopsy specimens to be associated with plaque rupture [9]. The third characteristic of high-risk plaque is inflammation. A high degree of macrophage infiltration into and around the fibrous cap has been found in specimens of acute plaque rupture [6]. These macrophages release matrix-digesting enzymes such as macrophage myeloperoxidase responsible for the degradation of the fibrillar collagen that forms the structure of the fibrous cap [10].

Yet even these advances in our ability to describe highrisk plaques significantly oversimplify the issue. They are anatomical characteristics that ignore more functional forces such as the underlying thrombogenicity of the blood, systemic inflammation, mechanical stress, vasomotor tone, etc. [11, 12]. Consider several studies that have challenged the notion that ACS result only from pathology at a focal site in the coronary bed. An intravascular ultrasound (IVUS) study performed by Rioufol et al. [13] has shown that 79\% of the patients with ACS have evidence of two or more plaque ruptures. Goldstein et al. [14] looked at angiograms of 253 patients presenting with an acute MI and found that $39.5 \%$ of them had evidence of multiple complex plaques at presentation. Buffon et al. [15] found an elevated level of neutrophil myeloperoxidase in the great cardiac vein of patients having unstable angina thought to be due to lesions in the left anterior descending (LAD) or in the right coronary artery, despite the fact that the right coronary artery territory is not drained by the great cardiac vein. The neutrophil activation throughout the coronary bed led them to conclude that unstable angina is a generalized endothelial inflammatory process, challenging the concept of a single vulnerable plaque. Goldschmidt-Clermont et al. [16] described plaque rupture as a result of an imbalance between plaque cell injury (a local process) and plaque repair (a systemic process driven by marrow-derived cellular elements).

To complicate the picture further, the above story of the precipitating characteristics of plaque rupture does not neatly fit the findings of comprehensive reviews of postmortem studies [11]. In 33\% of ACS, there is only a superficial erosion of a markedly stenotic and fibrotic plaque with overlying thrombosis, without frank rupture or significant inflammatory cell infiltrate [6]. These represent the phase four lesions that undergo remodeling and become functionally stable. They seem to occur most 
commonly in those with prothrombotic risk factors, i.e., tobacco use, low LDL, and diabetes with its exaggerated platelet aggregation. Ruptured plaque has been found in nearly $25 \%$ of patients with CAD who died from noncardiac causes [17]. We also know that thrombosis at the site of plaque is related not only to characteristics of the plaque, but also to irregularity or denudation of the lumen and slow flow due to upstream or downstream stenoses [18].

There is a discrepancy between the fixed anatomical hypothesis and the complex functional reality of acute plaque rupture. Together with the association of systemic inflammatory markers such as C-reactive protein (CRP) with risk for the development of ACS [19-21], the above findings underscore the systemic nature of the disease. We may be missing the boat in terms of prevention of acute events by focusing only on isolating and treating high-risk plaques. Yet if we keep in mind the systemic forces that play into plaque destabilization, we may be able to incorporate both anatomical and functional information to develop a more realistic understanding of the mechanisms of acute coronary events in 'at-risk' patients (fig. 3).

\section{Imaging of the Coronary Arteries in Search of High-Risk Plaque}

The innovative ideas and technology behind imaging techniques have stayed abreast with our rapidly evolving understanding of the pathophysiology of ACS. Multiple invasive and noninvasive modalities are capable of imaging the coronary circulation. Information gathered from these imaging techniques allows us to assess anatomical and functional characteristics of local sites of atherosclerotic plaque as well as the overall plaque burden.

What follows is a review of the different modalities available to image the coronary arteries, concentrating on the visualization of atherosclerotic lesions. The review begins with the invasive methods, continues with noninvasive methods, and concludes with some of the newest techniques for localizing high-risk lesions.

\section{Coronary Angiography}

The development of coronary angiography in the 1950s provided the first in vivo imaging of the coronary arteries. It has become our standard invasive method for diagnosing CAD. Histopathological correlations of angiographic lesion morphologies have shown that lesions with irregular borders and intraluminal lucencies correspond

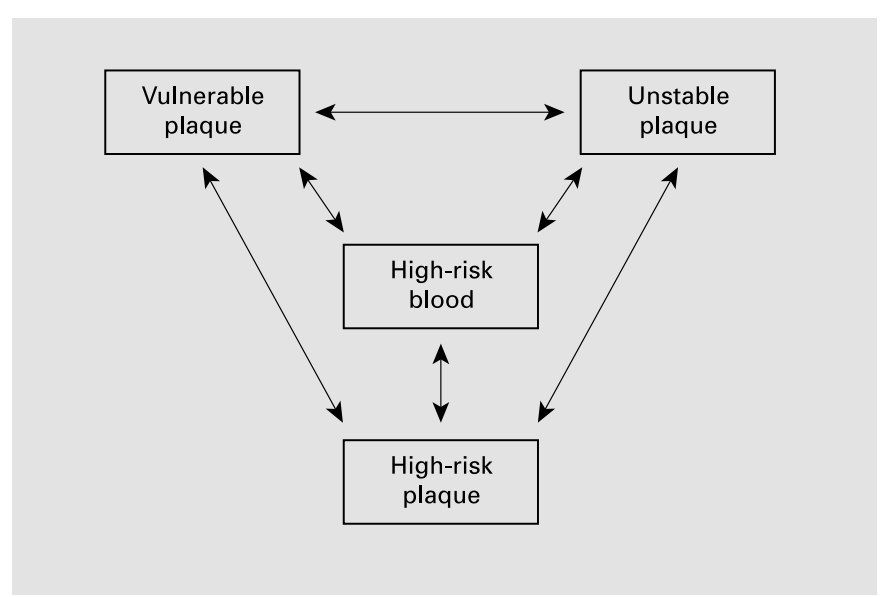

Fig. 3. The spectrum of plaque vulnerability, instability, and, hence, risk is dynamic and is further modulated by the blood environment. [Circulation 2003;107:2077.]

to complex plaque with associated hemorrhage and thrombosis. Concentric stenoses with smooth borders and no intraluminal lucencies correspond to more stable plaques [22].

The main limitation of angiography is that it only provides information about the vessel lumen without characterizing the vessel wall. Angiographic stenosis can only be diagnosed by comparing an area to an adjacent reference segment that is assumed to be disease free. Visual assessment of the degree of stenosis is prone to significant operator variability. Maybe most importantly, we know that the degree of lumenal stenosis does not correlate with the risk of a lesion leading to an ACS and that these events often occur from rupture of a modestly stenotic plaque not detectable by angiography [4, 23]. For these reasons, angiography is not the optimal modality for identifying 'high-risk' lesions.

\section{Coronary Angioscopy}

Angioscopy is very sensitive for identifying plaque and intravascular thrombi [8]. Plaques seen as yellow on angioscopy are lipid rich on histopathology, often have an irregular intimal surface, and are commonly found in patients with ACS [24]. White plaques contain more fibrous tissue, are less prone to rupture, and are more commonly observed in patients with stable angina. One study attempted to predict coronary events on the basis of the angioscopic appearance of plaque in 157 patients. Thirty-nine patients had yellow plaques, and 118 had white plaques [25]. At 12-month follow-up, acute coro- 
Fig. 4. Early plaque accumulation in human coronary arteries is associated with compensatory enlargement of vessel size (positive remodeling). In the early phases of atherosclerosis development, when CAD is minimal, the luminal size is not affected by plaque growth because of expansion of the EEM and enlargement of vessel size; this represents 'positive remodeling'. As CAD becomes moderate, there is no further increase in vessel size, but rather the plaque encroaches on the lumen which shrinks. These complex changes of lumen, plaque, and EEM may also affect plaque regression. With permission from ref. 27.

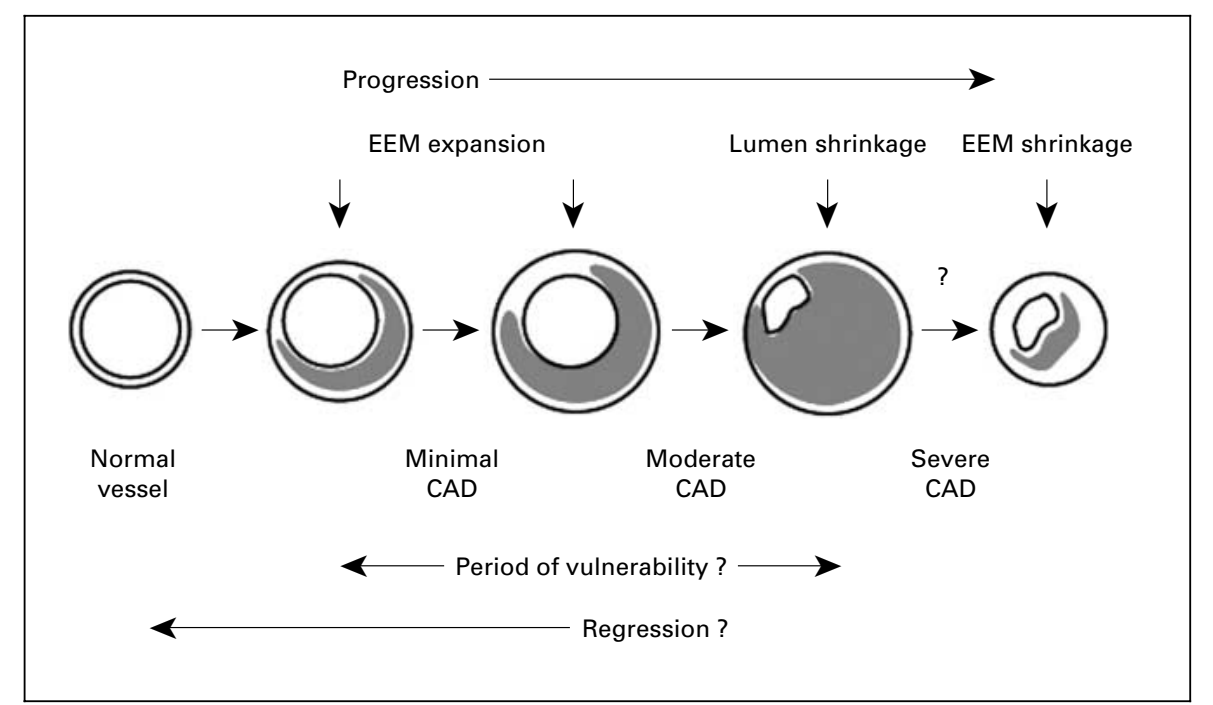

nary events, confirmed by angioscopy to be the result of thrombus arising from the site of the ruptured culprit plaque, were more common in association with yellow than white plaques ( 28 vs. $3 \%$ ). Angioscopy remains primarily a research tool because of its multiple limitations. It is an invasive method that is unable to cross stenotic lesions, visualize the proximal $2 \mathrm{~cm}$ of the main coronary arteries, enter small-caliber vessels, or provide information about the layers of the vessel wall [26].

\section{Intravascular Ultrasound}

We know that angiographically normal vessels can contain significant plaque. In 1987, based on his work with postmortem and animal models, Glagov et al. [27] introduced the principle of positive remodeling by which a diseased vessel expands outward at the site of plaque preserving the area of the lumen (fig. 4). Only at a very advanced stage of the plaque is the lumen area reduced to the point that the plaque becomes evident by angiography. This was the first pathophysiological explanation for why the degree of stenosis does not correlate with the incidence of ACS.

The desire to obtain direct images of the vessel wall at the site of suspected atherosclerosis, to a greater depth, and without the limitations of angioscopy led to the use of IVUS. IVUS is performed as part of cardiac catheterization using catheters equipped with ultrasound probes at their tip. The IVUS probe utilizes high ultrasound frequencies (20-50 MHz) to generate a gray-scale image with an axial resolution of $150 \mu \mathrm{m}$ and a lateral resolution of $250 \mu \mathrm{m}$ [28]. The catheter tip is placed just distal to the lesion and withdrawn during continuous imaging, providing a series of tomographic images of the vessel wall. IVUS is able to assess areas that are difficult to visualize by angiography such as diffusely diseased segments, eccentric lesions, ostial or bifurcation lesions, left main lesions, and foreshortened vessels.

IVUS is able to distinguish some of the components of atherosclerotic plaque. Highly echoreflective regions with acoustic shadows correspond to calcified tissue. Hypoechoic regions correspond to lipid-rich tissue. Hyperechoic regions represent fibrous tissue [26]. This allows for a general assessment of a plaque as 'soft' or 'hard' based on the relative amount of lipid versus fibrous tissue in the core. The resolution of IVUS does not allow it to quantify the thickness of the fibrous cap or the degree of inflammatory cell infiltrate.

By distinguishing the blood-intimal border and the external elastic membrane (EEM), IVUS is able to provide precise measurements of lumen area, intima-media area, and EEM. Using these measurements, IVUS has confirmed the in vitro findings of Glagov that vessels may appear normal by angiography at the site of significant lesions due to positive remodeling [29] (fig. 5). It has also been shown that the process of negative remodeling, leading to lumenal narrowing, occurs in more advanced lesions and in response to stent placement (restenosis). Some vessels contain lesions with positive remodeling and other lesions with negative remodeling, suggesting that remodeling may be a focal phenomenon modulated by local hemodynamic changes. IVUS studies have looked at the relationship of types of remodeling and clin- 
Fig. 5. Example of positive remodeling. IVUS images of the proximal reference and lesion site are shown. The remodeling ratio (EEM area lesion/EEM area proximal reference) is 1.32 . Reprinted with permission from J Am Coll Cardiol 2001;38:297.

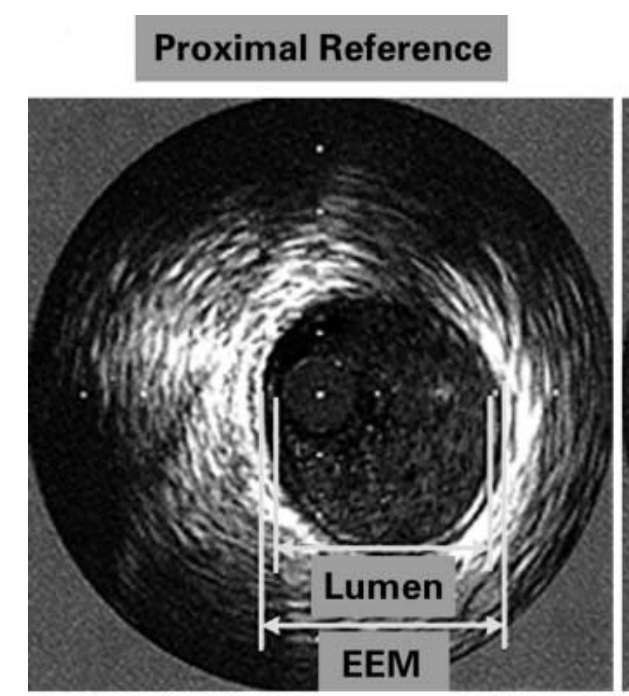

EEM area $=14.9 \mathrm{~mm}^{2}$

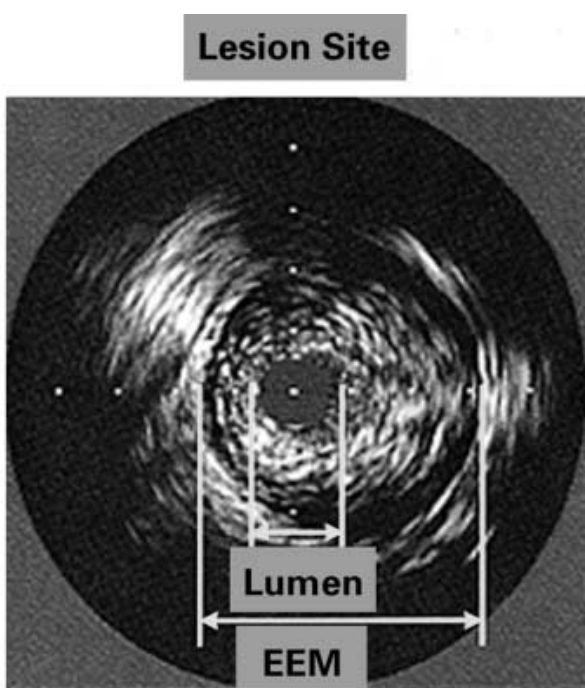

EEM area $=18.9 \mathrm{~mm}^{2}$ ical presentation of patients with CAD. One study looked at 85 patients with unstable and at 46 patients with stable coronary syndromes using IVUS. Positive remodeling was significantly more common in unstable versus stable lesions ( 51.8 vs. $19.6 \%$ ), whereas negative remodeling was more common in stable versus unstable lesions (56.5 vs. 31.8\%) [30]. This supports the notion that most ACS arise from plaques that are minimally stenotic and may not be recognized by angiography. Could local inflammation and lipid infiltration be triggers of positive remodeling and in this way the precipitants of plaque rupture?

Takano et al. [31] used IVUS to look at 38 lesions previously characterized by angioscopy as being yellow or white plaques. Yellow plaques were described as those with large lipid cores and thin fibrous caps, whereas white plaques contained a thick fibrous cap with significant fibrous tissue throughout. These authors used IVUS to measure distensibility and stiffness of plaque as well as the degree of positive remodeling. They found that yellow plaques were characterized by increased distensibility, decreased stiffness, and positive remodeling. The white or stable plaques showed a decreased distensibility, an increased stiffness, and negative remodeling. Takano et al. [31] concluded that these characteristics of yellow plaques help explain their high risk for triggering ACS.

Yamagishi et al. [32] have also used IVUS to relate morphology of plaque to instability of plaque. They identified 114 sites of plaque by IVUS in patients with coronary disease that did not correlate with lesions $>50 \%$ by angiography. They prospectively followed these patients. Twelve patients had coronary events at one of the previously identified sites. In comparison to sites that did not become unstable, the culprit sites were characterized by a large plaque burden with an echolucent zone representing a lipid-rich core.

Kotani et al. [33] used IVUS to evaluate 78 coronary arteries in 38 consecutive patients with acute MI. They found that culprit plaques had three distinctive features by IVUS: positive remodeling, thrombus, and a large plaque mass, again confirming the hypothesis that there are lesion-specific morphologies that determine plaque instability. The study is limited by the fact that the vessels were evaluated after the acute MI and that the diagnosis of thrombus by IVUS can only be made presumptively. Interestingly, in this study, multiple plaque ruptures were seen only in $10.5 \%$ of the patients after acute MI, unlike the $79 \%$ reported in the study performed by Rioufol et al. [13] that also used IVUS.

IVUS has been useful in diagnosing transplant vasculopathy, a diffuse disease of intimal thickening which is often missed by angiography. In a study of patients 1 year after transplantation, angiography identified disease in $10-20 \%$ of them, while IVUS identifed disease in $50 \%$ of those patients [34]. Another example of the sensitivity of IVUS is in cases of 'small vessels' found on angiography in diabetic patients. IVUS can show that this is actually a result of diffuse plaque accumulation rather than a focal area of stenosis [28]. Interventional cardiologists use 

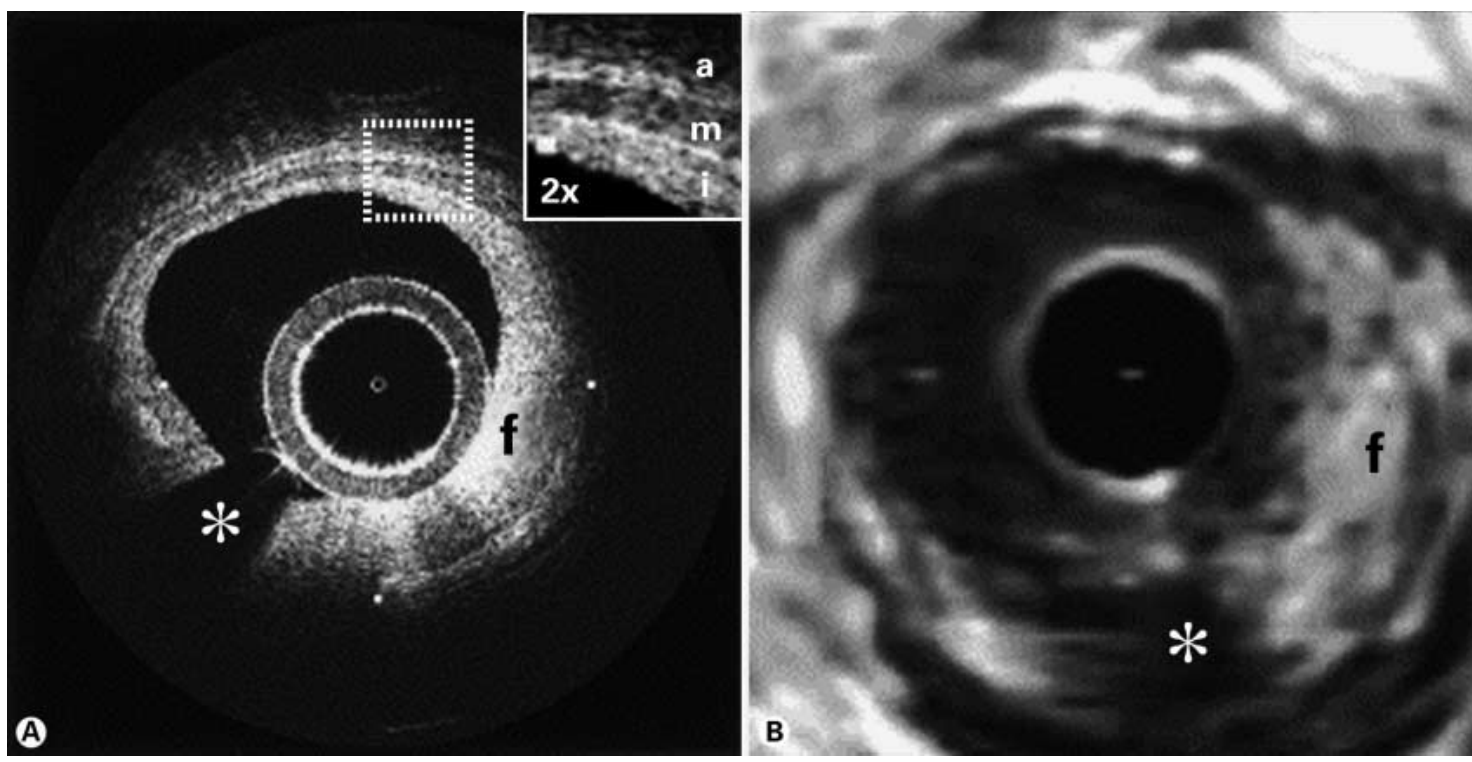

Fig. 6. Fibrous coronary plaque imaged in vivo by OCT (A) and IVUS (B). A From 9 o'clock to 2 o'clock, this OCT image demonstrates visualization of the intima with intimal hyperplasia (i), media (m), and adventitia (a). The internal and external elastic laminae are visible as signal-rich lines bordering the media (inset). A plaque extending from 2 o'clock to 9 o'clock contains a homogeneous, signal-rich region consistent with a fibrous plaque (f) that is partially obscured by a guidewire shadow artifact (asterisk). B In the corresponding IVUS image, the fibrous plaque (f) is also visualized. Tick marks, $1 \mathrm{~mm}$. Reprinted with permission from ref. 39.

IVUS to detail the eccentricity of plaque to select a lesion-specific interventional approach such as directional atherectomy. IVUS is also being used to gauge the response of lesions to lipid-lowering therapy.

IVUS has a number of limitations. The interpretation is based on visual inspection. Echogenicity and texture of different tissue may appear very similar. It is generally excellent at determining the thickness and the echogenicity of the vessel wall, but it does not consistently provide actual histology. It is difficult to distinguish between thrombus and lipid-rich plaque on IVUS. There is often significant artifact. Oblique-plane imaging when the probe is not perpendicular to the vessel wall can lead to distortion of the image. The $1-\mathrm{mm}$ catheter is too large to pass through severe stenoses [35].

Another ultrasound technology that has been used to assess the coronary arterial wall is high-resolution transthoracic echocardiography [36]. In one study of angiographically proven CAD in the LAD of 26 patients, alongside 29 controls, high-resolution transthoracic echocardiography was found to be sensitive enough to detect a difference in the wall thickness between diseased vessels and controls. Its resolution prevents it from being able to further characterize the constituency of the wall.

\section{Optical Coherence Tomography (OCT)}

OCT is similar in principle to ultrasound. Instead of sound, it directs infrared laser light at the tissue of interest. The OCT probe is mounted on an intravascular OCT catheter. OCT's main advantage over IVUS is its resolution. It has an axial resolution of $2-30 \mu \mathrm{m}$ and a lateral resolution of 5-30 $\mu \mathrm{m}$ [8]. This allows OCT to better differentiate between intimal wall and lipid-rich core [37] as well as to measure the thickness of the fibrous cap [38].

The trade-off in achieving this resolution is the limited depth of penetration of OCT (1-2 mm) [8]. For this reason, OCT cannot assess the extent of the lipid pool or measure the EEM to determine positive versus negative remodeling. Another limitation of OCT is that light is absorbed by blood. This necessitates displacement of the blood volume with saline during imaging. The short time window $(2 \mathrm{~s})$ available for imaging while the blood is displaced makes it difficult to assess long vessels [39].

Jang et al. [39] attempted to validate the use of OCT for plaque visualization. They obtained IVUS and OCT image pairs of 42 coronary plaques (fig. 6). All of the plaques, areas of calcification, and echolucent areas (thought to correspond to lipid pools) identified by IVUS were also seen by OCT. The higher resolution of OCT 
allowed for detection of intimal hyperplasia and internal and external elastic laminae. There was decreased shadowing from calcium in the wall, allowing for improved imaging of adjacent tissue. Finally, OCT was capable of identifying thin fibrous plaques $(<65 \mu \mathrm{m})$, the second of the three components associated with unstable plaque. OCT has now actually been shown to be able to quantify the amount of macrophages within the fibrous cap.

OCT has several potential applications. It can advance our understanding of the morphological features that determine plaque vulnerability, and it can be used to guide lesion-specific interventional therapy and to follow plaque regression in response to genetic or pharmacologic intervention.

\section{Near-Infrared (NIR) Spectroscopy}

Spectroscopy directs light of specific wavelengths onto tissue and collects light scattered from the tissue into a spectrometer. Each tissue has a unique pattern of light absorbance at different wavelengths. This allows for the creation of a spectroscopic 'fingerprint' for each tissue type. Spectroscopy can be performed in the coronary bed. Spectral modeling is used to discriminate coronary arterial tissue into three categories: nonatherosclerotic plaque, noncalcified plaque, and calcified plaque [40] (fig. 7).

Moreno et al. [41] have studied the use of NIR spectroscopy to identify high-risk plaque. Their in vitro studies showed that spectroscopy could identify lipid pools, thin fibrous caps, and inflammatory cell infiltrates in autopsy specimens of human aortas [41]. In vivo studies using a NIR catheter system are now ongoing in humans in an attempt to identify high-risk plaque in patients with known coronary disease undergoing elective intervention [40].

NIR has been used to image the intraplaque activity of cathepsin B, a protease thought to be involved in plaque rupture [42]. Spectroscopy could potentially be used as a complement to an imaging modality such as IVUS or OCT to combine visual inspection of anatomy with the tissue characterization afforded by spectroscopy. One group has shown that plaque $\mathrm{pH}$ and lactate level can be measured by a NIR spectroscopy probe [43].

\section{Computed Tomography (CT) for Evaluation of the Coronary Arteries}

Electron beam CT (EBCT) is an X-ray imaging device that uses three-dimensional acquisition of multiple parallel tomograms (spatial or temporal slices) to view the heart. The data are acquired through a sequence of 50$100 \mathrm{~ms}$ long 3- to 6-mm slices obtained during a breath-

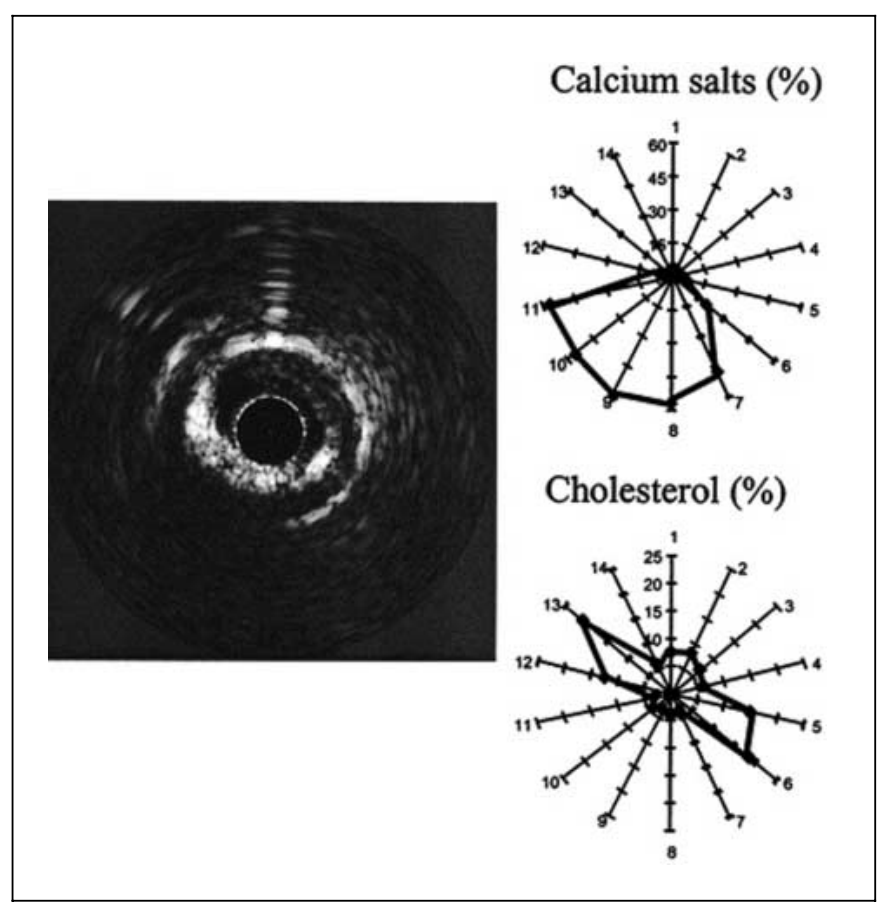

Fig. 7. IVUS image of a calcified coronary artery (left) and the relative weights of calcium salts (top) and total cholesterol (bottom) in the same artery plane determined by Raman spectroscopy. The IVUS images were obtained from an intact artery segment which was marked by a needle (12 o'clock). Raman spectra were obtained from the artery after it was opened. The IVUS image shows a calcification, in agreement with the calcium salts detected with Raman spectroscopy. Cholesterol was detected with Raman spectroscopy, but ould not be discriminated within the IVUS image. Reprinted with permission from ref. 8.

hold sequence of approximately $40 \mathrm{~s}$ from the aortic root to the apex of the heart. X-ray radiation passes through the patient and is detected by two stationary detector rings [26]. More recently four-slice ultrafast or spiral CT has been adapted for coronary calcium assessment [44]. Ultrafast CT minimizes cardiac and respiratory motion artifacts and has made coronary calcium scanning more widely available. A study can be completed within less than $15 \mathrm{~min}$. In addition to assessing coronary artery calcification, CT has been used for noninvasive coronary angiography and assessment of myocardial perfusion.

CT has the unique capability of not only detecting but also quantifying coronary calcium deposits. Calcium is identified as a tissue density of $>130$ Hounsfield units. The levels of coronary calcium correlate strongly with the overall atherosclerotic plaque burden [45], the presence of high-grade stenotic lesions [46], positive remodeling [47], and with increased cardiac events and mortality [48]. In a 
meta-analysis looking at 1,662 patients with EBCT and coronary angiography, the pooled sensitivity and specificity of EBCT were 92 and 51\%, respectively [49]. Another meta-analysis showed that a calcium score above the median value for the population is associated with an unadjusted odds ratio of 4.2 for an MI or death [50].

The most recent ACC/AHA recommendations on the use of calcium scoring published in 2000 did not find compelling evidence to recommend calcium scoring for screening asymptomatic patients [51]. The report was concerned with the poor specificity of the studies potentially leading to unnecessary workup. In addition, there was no clear evidence at that time that calcium scoring could predict hard cardiac events independently of traditional risk factors or change therapy leading to the prevention of future cardiac events. The limitations of calcium scoring have been addressed by retrospective analysis of previous studies and by more recent studies. Some of the poor specificity can be attributed to 'referral bias' due to the number of low-risk, asymptomatic patients enrolled in the previous studies.

The St. Francis Heart Study [52] has looked at 5,585 asymptomatic men and women between 50 and 70 years of age with EBCT. Following these patients for 4.3 years, the authors showed that elevated calcium scores predicted coronary events even after adjusting for standard risk factors. They found a relative risk for cardiac events of 9.5 for people with calcium scores $>100$ when compared with those whose scores are $<100$. Similarly, Kondos et al. [53] followed 5,635 patients, showing that the presence of any coronary calcium in these patients was associated with a statistically significant increase in cardiovascular death or MI. Park et al. [54] looked prospectively at nondiabetics without known CAD over a mean follow-up period of 6.5 years and showed that the coronary calcium score was a significant predictor of MI and death from CAD. They also found it to be independent of CRP in its association.

Though these studies have shown the incremental predictive ability of calcium scoring and brought the technology closer to mainstream clinical practice, it remains to be seen whether knowing a patient's calcium score will affect their therapy in a manner that prevents future events. Some clear benefits of EBCT are that it is noninvasive, can be performed in close to $10 \mathrm{~min}$, requires minimal patient cooperation, provides immediate results, costs one third the price of a nuclear imaging stress test, and involves 10-100 times less radiation than coronary angiography [55]. There are several clinical settings in which EBCT may be of value: screening of asymptomatic patients with intermediate risk for CAD to decide on the aggressiveness of medical therapy [44], evaluating low- to intermediate-risk symptomatic patients to decide whether to proceed with stress testing or coronary angiography, and following the progression of atherosclerosis through serial scans, while a patient is receiving lipid-lowering therapy.

There are several limitations to the use of calcium scoring. Calcium can be found in both high-risk and stable plaques and thus cannot be used to distinguish patients who will develop an ACS from those who will have stable angina [56]. The prevalence of detectable calcium increases with age. For men the likelihood is equivalent to their age, and for women it is $10-15$ points below their age. African-Americans have been shown to be significantly less likely than whites to have coronary calcification despite a higher prevalence of risk factors such as hypertension and smoking [57]. In addition, there remains significant interobserver variability and problems with the reproducibility of calcium scoring [48].

Intravenous contrast EBCT can now be used to create three-dimensional images of the major epicardial coronary arteries with tomographic imaging during a single breath-hold (fig. 8). When compared with coronary angiography in 200 patients, EBCT demonstrated a sensitivity and specificity of approximately 80 and 90\%, respectively, for a luminal stenosis of $>50 \%$ [58]. The major limitations of noninvasive angiography by $\mathrm{CT}$ remains the image quality. In a study of 125 patients, $25 \%$ of 500 coronary segments were not adequately visualized. Since imaging occurs during end-diastole, the right coronary artery and the left circumflex artery, which run in the coronary groove, may not be well visualized as a result of motion during diastolic atrial contraction [59]. Another problem is artifact from respiratory motion and from heavy calcification. The newer four-slice detector systems are showing an improved image quality over the older scanners. There is still significant variability in technique from center to center, making it difficult to give general recommendations about its use. Finally, as with coronary angiography, CT angiography is unable to characterize specific lesions in enough detail to identify the features of high-risk plaque. There is likely to be a role for CT angiography, and we await the determination of the most appropriate patient population for its application. Some proposed uses are in patients with atypical chest pain and in patients with previously equivocal stress tests.

One novel application of contrast CT technology to attempt to isolate high-risk lesions is the use of nanoliposome encapsulated iohexol. This substance is taken up by macrophages and enhances on $\mathrm{CT}$. It provides a potential 


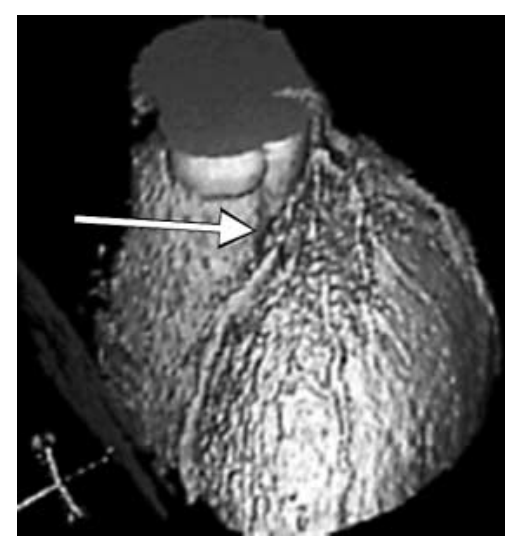

Shaded Surface Display

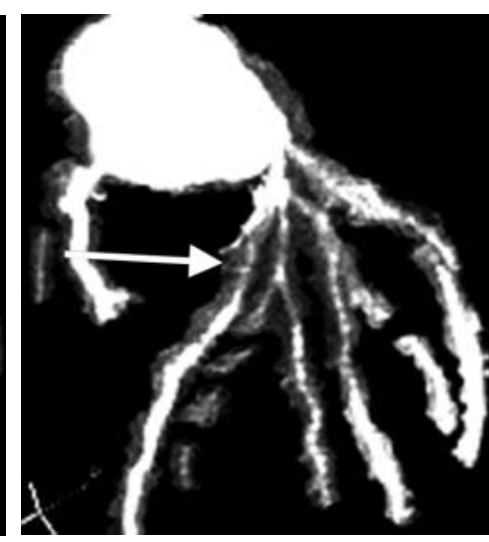

Maximum Intensity Projection

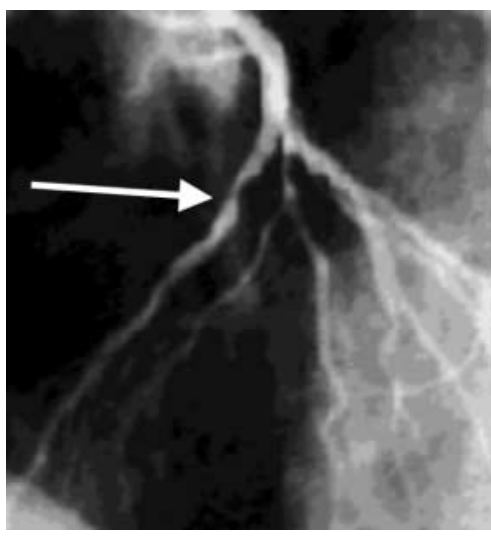

Selective Angio

Fig. 8. Coronary angiography using EBCT. Three-dimensional reconstructions of proximal coronary artery anatomy using electron-beam CT. A selective angiogram (right panel) demonstrates a $60 \%$ luminal narrowing (arrow) of the proximal LAD and some moderate disease of the first diagonal branch. Narrowing of the same region of the LAD is noted on both the shaded surface display (left panel; arrow) and maximum intensity projection (middle panel; arrow).

method for in vivo detection of inflammation and macrophage infiltration in active plaques [60].

\section{Magnetic Resonance Imaging (MRI)}

MRI represents the best noninvasive technology for imaging the three traditional components of high-risk plaque - necrotic core, fibrous cap, and inflammatory infiltrate. MR has a high spatial resolution and is able to differentiate components of plaque based on features such as chemical composition, water content, molecular motion, or diffusion [61]. MR images without ionizing radiation. A patient is subjected to a high local magnetic field which aligns the protons in the body. The protons are excited by a radiofrequency pulse and the signals detected by receiver coils. The timing of the excitation pulses and the magnetic field gradients determine the image contrast. The quality of the final image is determined by the signal, the contrast, and the level of background noise [26].

MRI has been used to image and characterize plaques in the carotids, aided by their superficial location and relative absence of motion. T2-weighted images have been quantified in vivo before surgery and correlated with in vitro values after endarterectomy [62]. Hatsukami et al. [63] introduced the use of bright-blood MRI to assess thickness and integrity of the fibrous cap in carotid artery plaques. These authors showed that the observation of fibrous cap rupture correlated with a recent history of transient ischemic attack or stroke. An excellent correla- tion has also been shown between MRI and transesophageal echocardiography assessment of plaque in the thoracic aorta [64].

In the coronary bed, MRI has been used to assess overall plaque size, necrotic core size, fibrous cap composition, and intraplaque hemorrhage. Bright areas on T2weighted images correspond to fibrous tissue, whereas dark areas correspond to lipid-rich regions. MRI is also unique in its ability to visualize thrombus and assess its size and anatomic location on T2-weighted images at least $48 \mathrm{~h}$ after thrombus formation [65]. MRI of the coronary vessel wall can be performed with high-resolution, blackblood sequences that minimize the signal from the blood. Fayad et al. [66] have used this technique to image epicardial coronary vessels and showed a statistically significant difference in wall thickness between normal subjects and patients with angiogram-proven stenoses of $>40 \%$.

MRI has been used in an experimental setting to monitor progression and regression of plaque. There are preliminary data showing a role for MRI in documenting arterial remodeling at the site of native atherosclerosis [67]. Corti et al. [68] showed that lipid-lowering therapy in asymptomatic hyperlipidemic patients led to regression of atherosclerotic lesions in the carotids and aorta at 12 months. The same group has used MRI to follow plaque in human patients on lipid lowering therapy with statins [68]. They showed that despite an immediate hypolipidemic effect, there was a delayed decrease in the vessel wall area at 12 months with no change in lumen 


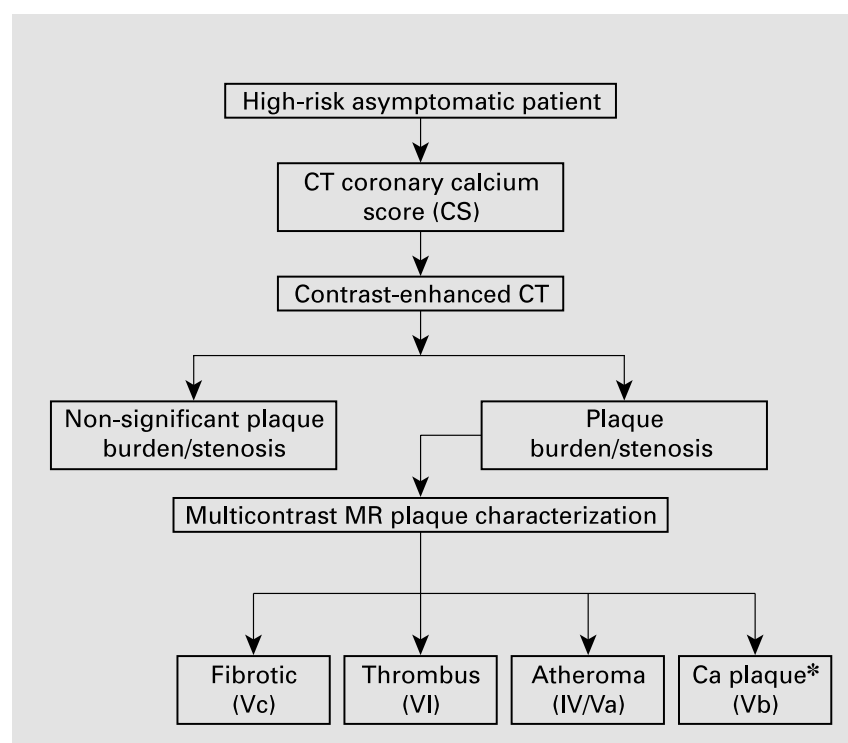

Fig. 9. Flow chart of a pilot study being conducted at the Mount Sinai Medical School for the detection of CAD and the characterization of atherosclerotic plaques with the use of the combination of MDCT and MRI. *Also identified by CT. From ref. 61, with permission.

area [69]. There has also been 10-year follow-up on a carotid MRI study showing reduced plaque lipid content though unchanged overall size in patients receiving lipidlowering therapy [70].

MRI contrast agents have been used to enhance components of the vessel wall and to identify inflammation and thrombus. Currently, the only clinically approved agents are gadolinium based. On T1-weighted images of carotid arteries a gadolinium-based agent has been shown to enhance areas of plaque rich in microvascularization, a marker of local inflammation [71]. Fibrin-targeted, paramagnetic, lipid-encapsulated perfluorocarbon nanoparticles, formulated with gadolinium, bind densely to fibrin clots and potentially could allow MRI to detect microthrombi that form on the intimal surface of unstable plaque [72]. Ruehm et al. [73] have shown that ultrasmall superparamagnetic iron oxides are phagocytosed by macrophages in atherosclerotic plaque of hyperlipidemic rabbits in a quantity sufficient to be detected by MRI. Kooi et al. [74] have extended the use of ultrasmall superparamagnetic iron oxides to in vivo imaging of macrophages in human carotid plaques. There is also the potential to develop contrast agents that target matrix metalloproteinases and enhance areas rich in proteolytic activity [75].
The main limitations to the use of MRI for evaluating coronary plaque are cardiac and respiratory motion artifact, nonlinear course of vessels, and small size and location of vessels [76]. Patient breath-holding has been the main technique used to minimize motion artifact [77]. Newer techniques use navigator gating to assess cardiac and diaphragmatic positions, compensate for motion, and thus eliminate the need for breath-holding [75, 78]. Further advances in external coils and imaging acquisition should allow for thinner slices and better quality images [75]. Acquisition of isotropic voxels, facilitating reconstruction of the coronary arteries in exhaustive views, can compensate for vessel tortuosity [79]. Semiautomatic image-processing techniques have been developed to better quantify vessel wall area, volume, and overall plaque burden [75]. Other experimental approaches to evaluating plaque are intravascular and transesophageal MRI. Finally, centers are currently exploring the possibility of virtual, real-time MRI to guide vascular intervention.

One proposed approach to the use of noninvasive plaque imaging is below. It involves utilizing both $\mathrm{CT}$ and MRI: using CT to identify patients with a large burden of disease and then MRI to further define specific sites of concerning plaque (fig. 9, 10).

MRI has also been explored as a noninvasive method for coronary angiography. A seven-center study performed coronary magnetic resonance angiography (MRA) on 109 patients receiving elective X-ray coronary angiography for suspected CAD [80]. The mean performance time of coronary MRA was $74 \mathrm{~min}, 84 \%$ of the proximal and mid-segments of the coronary arteries were interpretable, and 78 of $94(83 \%)$ significant stenoses $(>50 \%)$ were detected by MRA. The authors calculated a sensitivity of 93\% for diagnosing any coronary disease and one of $100 \%$ for identifying left main or three-vessel disease. The specificities were 42 and $85 \%$, respectively. The negative predictive value of MRA for any CAD in this study was $81 \%$. Further analysis of these data shows that if the goal is to avoid X-ray coronary angiography in patients without CAD, then coronary MRA will save $20 \%$ of the patients from needing the invasive test. If the goal is only to identify those with left main or three-vessel disease, then coronary MRA could save $69 \%$ of the patients from X-ray angiography [61]. MRA is still limited in its ability to image smaller vessels and overcome motion artifacts, though navigator gating is improving the latter at the expense of longer study times. 
Fig. 10. MRI and CT plaque characterization. Coronary artery lipid-rich plaque. A Cross-sectional ex vivo T2-weighted MRI of a human LAD with a lipid-rich lesion (arrow). B Multislice CT image of the same lesion (arrow), showing the typical low density of lipid-rich tissue (44 Hounsfield units). C Corresponding histopathological section with a large extracellular lipid pool. From ref. 61 , with permission.
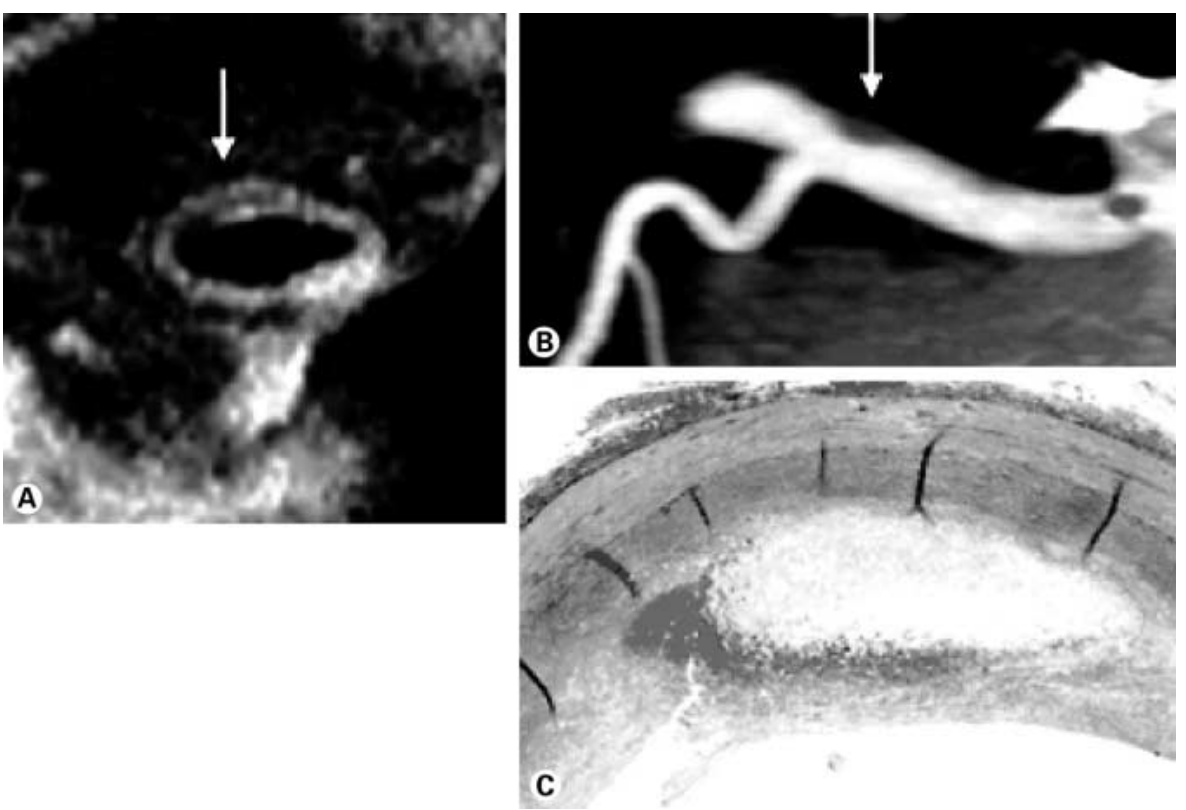

\section{Thermal Detection of High-Risk Plaque}

There has now been a move beyond strictly anatomic assessment of plaque to identify local markers of inflammation that may reflect plaque instability. One of these markers is temperature. It is known that macrophages are present in active or inflamed plaque. Macrophages are metabolically very active cells. The uptake of glucose and the consumption of oxygen by activated macrophages cause an increase in the local temperature. Once the inflammatory cells exhaust their supply of oxygen, a degree of anaerobic metabolism ensues, leading to local acidosis [81].

Ex vivo studies using specimens obtained after carotid endarterectomy showed that the temperature increases directly in relation to the density of macrophages and inversely to the density of smooth muscle cells present in the plaque [82]. Another study looking at atherosclerotic plaque in humans and rabbits showed that plaques with large lipid cores have higher temperatures and lower $\mathrm{pH}$ values, whereas calcified plaques have lower temperatures and higher $\mathrm{pH}$ values [83].

Several groups have begun to use intravascular thermography catheters to confirm this temperature heterogeneity. Stefanadis et al. [84] compared temperatures measured at the site of plaque in patients with stable angina, unstable angina, and acute MI to temperatures measured in control vessels. 20, 40, and $67 \%$ of stable angina, unstable angina, and acute MI patients, respectively, showed temperature heterogeneity in comparison to none in the control vessels. The same group found a strong correlation between increased temperature heterogeneity and elevated levels of systemic inflammatory markers, CRP, and serum amyloid A [85].

Lesions with positive remodeling as seen by IVUS and lesions with high levels of matrix metalloproteinase- 9 also have an increased temperature heterogeneity [86]. The temperature difference between atherosclerotic plaque and normal vessel wall has now been shown to be an independent predictor of adverse cardiac events [87]. Finally, the administration of atorvastatin to patients with CAD decreases the heat production at the site of culprit lesions [88].

Thermography has now moved into clinical trials to assess its safety and reproducibility. It provides us with a tool to combine anatomic information with functional information in an attempt to identify high-risk plaques and high-risk patients.

\section{Additional Experimental Methods of Detecting High-Risk Plaque}

A murine antibody to oxidized LDL has been shown to bind and identify lipid-rich atherosclerotic lesions in mice. These antibodies have been tagged with $\left[{ }^{125} \mathrm{I}\right]$, and their uptake has been measured to provide a quantification of the plaque burden [89]. Recently, a human anti- 
body to oxidized LDL has been developed and is being used on a research level to identify lipid-rich lesions. These antibodies can be tagged with appropriate labels for nuclear, magnetic resonance, or ultrasound imaging.

Another method that targets inflammatory components of plaque is the use of contrast ultrasound. Microbubble contrast agents have been designed to target leukocytes on inflamed endothelium or endothelial cell adhesion molecules on the plaque surface [90]. Ultrasound is then used to identify the destination of these microbubbles. The advantage of this new technique is that it is inexpensive, portable, and involves familiar technology.

$\left[{ }^{18} \mathrm{~F}\right]$ fluorodeoxyglucose is a glucose analogue taken up by cells in proportion to their metabolic activity. Rudd et al. [91] combined positron emission tomography and CT to show that $\left[{ }^{18} \mathrm{~F}\right]$ fluorodeoxyglucose accumulates in macrophage-rich portions of human carotid artery atherosclerotic plaques with a significantly higher uptake in symptomatic than in asymptomatic lesions. Their work suggests that $\left[{ }^{18} \mathrm{~F}\right]$ fluorodeoxyglucose-positron emission tomography may be useful in imaging and even quantifying the degree of inflammation in a plaque.

\section{Concluding Remarks}

Our imaging techniques have advanced to the point of being able to identify the key features of a high-risk plaque. IVUS and OCT are useful imaging modalities, but are likely to remain the tools of interventional cardiologists and researchers for guiding decisions in the catheterization laboratory and furthering our understanding of the mechanism of ACS. CT assessment of the coronary arteries via calcium scoring has already reached the mainstream of clinical practice and provides a sense of overall atherosclerotic burden. However, it is currently unable to distinguish high-risk from stable plaque. High-resolution MRI is probably the most promising technology because of its ability to noninvasively characterize and quantify plaque composition and microanatomy. It will become even more valuable with the use of contrast agents directed at the inflammatory components of plaque. Yet it is still in a growth stage, as the technical limitations to more universal use get worked out. Newer techniques such as thermography, positron emission tomography, and contrast ultrasound provide us with a functional clue to the inflammatory activity at the site of the lesion. The future is likely to lead to the use of multiple imaging modalities to create the most comprehensive evaluation of plaque.

Sometimes a long road of progress brings one back to the starting point. In 1856 Virchow described the three components contributing to atherothrombosis: the vessel wall, the coagulability of the blood, and the degree of blood stasis. Our growing knowledge of the pathophysiology of ACS suggests that the highest-risk patients for coronary events are those for whom all three of these factors are involved. ACS prevention cannot be reduced to the localization of a high-risk plaque when the coronary bed contains multiple plaques at different stages of development. Imaging techniques will supplement, though clearly not replace, the information gained from assessing a patient's traditional risk factors and signs of increased systemic inflammation. Imaging-derived plaque characteristics will be combined with local and systemic measures of thrombogenicity, flow, and inflammation to create a risk profile for an individual. We are only beginning to learn how to gather these data and how to use them to both diagnose coronary disease earlier and treat it more effectively.

\section{References}

1 Ambrose JA, Tannenbaum MA, Alexopoulos D, Hjemdahl-Monsen CE, Leavy J, Weiss M Borrico S, Gorlin R, Fuster V: Angiographic progression of coronary artery disease and the development of myocardial infarction. J Am Coll Cardiol 1988;12:56-62.

2 Little WC, Constantinescu M, Applegate RJ, Kutcher MA, Burrows MT, Kahl FR, Santamore WP: Can coronary angiography predict the site of a subsequent myocardial infarction in patients with mild-to-moderate coronary artery disease? Circulation 1988;78:1157-1166.
3 Fuster V, Fayad ZA, Badimon JJ: Acute coronary syndromes: Biology. Lancet 1999; 353(suppl 2):SII5-SII9.

4 Falk E, Shah PK, Fuster V: Coronary plaque disruption. Circulation 1995;92:657-671.

5 Libby P: Molecular bases of the acute coronary syndromes. Circulation 1995;91:2844-2850.

6 Virmani R, Kolodgie FD, Burke AP, Farb A, Schwartz SM: Lessons from sudden coronary death: A comprehensive morphological classification scheme for atherosclerotic lesions. Arterioscler Thromb Vasc Biol 2000;20:12621275 .
7 Davies MJ, Richardson PD, Woolf N, Katz DR, Mann J: Risk of thrombosis in human atherosclerotic plaques: Role of extracellular lipid, macrophage, and smooth muscle cell content. Br Heart J 1993;69:377-381.

8 Pasterkamp G, Falk E, Woutman H, Borst C: Techniques characterizing the coronary atherosclerotic plaque: Influence on clinical decision making? J Am Coll Cardiol 2000;36:13-21.

9 Burke AP, Farb A, Malcom GT, Liang YH, Smialek J, Virmani R: Coronary risk factors and plaque morphology in men with coronary disease who died suddenly. N Engl J Med 1997; 336:1276-1282. 
10 Sugiyama S, Okada Y, Sukhova GK, Virmani R, Heinecke JW, Libby P: Macrophage myeloperoxidase regulation by granulocyte-macrophage colony-stimulating factor in human atherosclerosis and implications in acute coronary syndromes. Am J Pathol 2001;158:879-891.

11 Maseri A, Fuster V: Is there a vulnerable plaque? Circulation 2003;107:2068-2071.

12 Gertz SD, Roberts WC: Hemodynamic shear force in rupture of coronary arterial atherosclerotic plaques. Am J Cardiol 1990;66:13681372.

13 Rioufol G, Finet G, Ginon I, André-Fouet X, Rossi R, Vialle E, Desjoyaux E, Convert G, Huret JF, Tabib A: Multiple atherosclerotic plaque rupture in acute coronary syndrome: A three-vessel intravascular ultrasound study. Circulation 2002;106:804-808.

14 Goldstein JA, Demetriou D, Grines CL, Pica M, Shoukfeh M, O'Neill WW: Multiple complex coronary plaques in patients with acute myocardial infarction. N Engl J Med 2000;343: 915-922.

15 Buffon A, Biasucci LM, Liuzzo G, D’Onofrio G, Crea F, Maseri A: Widespread coronary inflammation in unstable angina. $\mathrm{N}$ Engl J Med 2002;347:5-12.

16 Goldschmidt-Clermont PJ, Kandzari DE, Sketch MH Jr, Phillips HR: Inflammation, platelets, and glycoprotein IIb/IIIa inhibitors. J Invasive Cardiol 2002;14(suppl E):18E-26E.

17 Davies MJ: Stability and instability: Two faces of coronary atherosclerosis. The Paul Dudley White Lecture 1995. Circulation 1996;94: 2013-2020.

18 Casscells W, Naghavi M, Willerson JT: Vulnerable atherosclerotic plaque: A multifocal disease. Circulation 2003; 107:2072-2075.

19 Liuzzo G, Biasucci LM, Gallimore JR, Grillo RL, Rebuzzi AG, Pepys MB, Maseri A: The prognostic value of C-reactive protein and serum amyloid A protein in severe unstable angina. N Engl J Med 1994;331:417-424.

20 Ridker PM, Cushman M, Stampfer MJ, Tracy $\mathrm{RP}$, Hennekens $\mathrm{CH}$ : Inflammation, aspirin, and the risk of cardiovascular disease in apparently healthy men. N Engl J Med 1997;336: 973-979.

21 Ridker PM, Buring JE, Shih J, Matias M, Hennekens $\mathrm{CH}$ : Prospective study of $\mathrm{C}$-reactive protein and the risk of future cardiovascular events among apparently healthy women. Circulation 1998;98:731-733.

22 Levin DC, Fallon JT: Significance of the angiographic morphology of localized coronary stenoses: Histopathologic correlations. Circulation 1982;66:316-320.

23 Ambrose JA, Hjemdahl-Monsen CE: Arteriographic anatomy and mechanisms of myocardial ischemia in unstable angina. J Am Coll Cardiol 1987;9:1397-1402.

24 Thieme T, Wernecke KD, Meyer R, Brandenstein E, Habedank D, Hinz A, Felix SB, Baumann G, Kleber FX: Angioscopic evaluation of atherosclerotic plaques: Validation by histomorphologic analysis and association with stable and unstable coronary syndromes. J Am Coll Cardiol 1996;28:1-6.
25 Uchida Y, Nakamura F, Tomaru T, Morita T, Oshima T, Sasaki T, Morizuki S, Hirose J: Prediction of acute coronary syndromes by percutaneous coronary angioscopy in patients with stable angina. Am Heart J 1995; 130:195-203.

26 Fayad ZA, Fuster V: Clinical imaging of the high-risk or vulnerable atherosclerotic plaque. Circ Res 2001;89:305-316.

27 Glagov S, Weisenberg E, Zarins CK, Stankunavicius R, Kolettis GJ: Compensatory enlargement of human atherosclerotic coronary arteries. N Engl J Med 1987;316:1371-1375.

28 Schoenhagen P, Nissen S: Understanding coronary artery disease: Tomographic imaging with intravascular ultrasound. Heart 2002;88:9196.

29 Losordo DW, Rosenfield K, Kaufman J, Pieczek A, Isner JM: Focal compensatory enlargement of human arteries in response to progressive atherosclerosis: In vivo documentation using intravascular ultrasound. Circulation 1994; 89:2570-2577.

30 Schoenhagen P, Ziada KM, Kapadia SR, Crowe TD, Nissen SE, Tuzcu EM: Extent and direction of arterial remodeling in stable versus unstable coronary syndromes: An intravascular ultrasound study. Circulation 2000;101:598603.

31 Takano M, Mizuno K, Okamatsu K, Yokoyama S, Ohba T, Sakai S: Mechanical and structural characteristics of vulnerable plaques: Analysis by coronary angioscopy and intravascular ultrasound. J Am Coll Cardiol 2001;38: 99-104.

32 Yamagishi M, Terashima M, Awano K, Kijima M, Nakatani S, Daikoku S, Ito K, Yasumura Y, Miyatake K: Morphology of vulnerable coronary plaque: Insights from follow-up of patients examined by intravascular ultrasound before an acute coronary syndrome. J Am Coll Cardiol 2000;35:106-111.

33 Kotani J, Castagna M, Pinnow E, Chalak B, Bui A, Pichard A, Satler L, Suddath W, Waksman R, Laird J, Kent K, Weissman N: Intravascular ultrasound analysis of infarct-related and non-infarct-related arteries in patients who presented with an acute myocardial infarction. Circulation 2003;107:2889-2893.

34 Yeung AC, Davis SF, Hauptman PJ, Kobashigawa JA, Miller LW, Valantine HA, Ventura HO, Wiedermann J, Wilensky R: Incidence and progression of transplant coronary artery disease over 1 year: Results of a multicenter trial with use of intravascular ultrasound. Multicenter Intravascular Ultrasound Transplant Study Group. J Heart Lung Transplant 1995; 14(6 Pt 2):S215-S220.

35 Nissen SE, Yock P: Intravascular ultrasound: Novel pathophysiological insights and current clinical applications. Circulation 2001;103: 604-616.

36 Gradus-Pizlo I, Sawada SG, Wright D, Segar DS, Feigenbaum H: Detection of subclinical coronary atherosclerosis using two-dimensional, high-resolution transthoracic echocardiography. J Am Coll Cardiol 2001;37:1422-1429.
37 Brezinski ME, Tearney GJ, Weissman NJ, Boppart SA, Bouma BE, Hee MR, Weyman AE, Swanson EA, Southern JF, Fujimoto JG: Assessing atherosclerotic plaque morphology: Comparison of optical coherence tomography and high frequency intravascular ultrasound. Heart 1997;77:397-403.

38 Brezinski ME, Tearney GJ, Bouma BE, Izatt JA, Hee MR, Swanson EA, Southern JF, Fujimoto JG: Optical coherence tomography for optical biopsy: Properties and demonstration of vascular pathology. Circulation 1996;93: 1206-1213.

39 Jang IK, Bouma BE, Kang DH, Park SJ, Park SW, Seung KB, Choi KB, Shishkov M, Schlendorf K, Pomerantsev E, Houser SL, Aretz HT, Tearney GJ: Visualization of coronary atherosclerotic plaques in patients using optical coherence tomography: Comparison with intravascular ultrasound. J Am Coll Cardiol 2002; 39:604-609.

40 Moreno PR, Muller JE: Identification of highrisk atherosclerotic plaques: A survey of spectroscopic methods. Curr Opin Cardiol 2002. 17:638-647.

41 Moreno PR, Lodder RA, Purushothaman KR, Charash WE, O'Connor WN, Muller JE: Detection of lipid pool, thin fibrous cap, and inflammatory cells in human aortic atherosclerotic plaques by near-infrared spectroscopy. Circulation 2002;105:923-927.

42 Chen J, Tung CH, Mahmood U, Ntziachristos V, Gyurko R, Fishman MC, Huang PL, Weissleder R: In vivo imaging of proteolytic activity in atherosclerosis. Circulation 2002;105:27662771.

43 Khan T, Madjid M, Casscells W, Naghavi M: Visible/near-infrared optical catheter prototype accurately determines $\mathrm{pH}$ and lactate of atherosclerotic plaques; in: Imaging and Vulnerable Plaque. TCT 2002 [abstract].

44 Schmermund A, Mohlenkamp S, Erbel R: The latest on the calcium story. Am J Cardiol 2002; 90:12L-14L

45 Budoff MJ, Georgiou D, Brody A, Agatston AS, Kennedy J, Wolfkiel C, Stanford W, Shields P, Lewis RJ, Janowitz WR, Rich S, Brundage $\mathrm{BH}$ : Ultrafast computed tomography as a diagnostic modality in the detection of coronary artery disease: A multicenter study. Circulation 1996;93:898-904.

46 Mautner GC, Mautner SL, Froehlich J, Feuerstein IM, Proschan MA, Roberts WC, Doppman JL: Coronary artery calcification: Assessment with electron beam CT and histomorphometric correlation. Radiology 1994;192: 619-623.

47 Burke AP, Kolodgie FD, Farb A, Weber D, Virmani R: Morphological predictors of arterial remodeling in coronary atherosclerosis. Circulation 2002; 105:297-303.

48 Redberg RF, Vogel RA, Criqui M, Herrington D, Lima J, Roman M: 34th Bethesda Conference: Task force \#3 - What is the spectrum of current and emerging techniques for the noninvasive measurement of atherosclerosis. J Am Coll Cardiol 2003;41:1886-1898. 
49 Nallamothu BK, Saint S, Bielak LF, Sonnad SS, Peyser PA, Rubenfire M, Fendrick AM: Electron-beam computed tomography in the diagnosis of coronary artery disease: A metaanalysis. Arch Intern Med 2001;161:833-838.

50 O'Malley PG, Taylor AJ, Jackson JL, Doherty TM, Detrano RC: Prognostic value of coronary electron-beam computed tomography for coronary heart disease events in asymptomatic populations. Am J Cardiol 2000;85:945-948.

51 O'Rourke RA, Brundage BH, Froelicher VF, Greenland P, Grundy SM, Hachamovitch R, Pohost GM, Shaw LJ, Weintraub WS, Winters WL Jr: American College of Cardiology/American Heart Association Expert Consensus Document on electron-beam computed tomography for the diagnosis and prognosis of coronary artery disease. J Am Coll Cardiol 2000;36:326340.

52 Arad Y, Newstein D, Guerci A: Coronary calcification, coronary disease risk factors, and atherosclerotic cardiovascular events: The St. Francis Heart Study; in: American College of Cardiology Scientific Sessions 2003. Chicago 2003.

53 Kondos G, Hoff J, Sevrukov A, Daviglus M, Garside D, Devries S, Chomka E, Liu K: Electron-beam tomography coronary artery calcium and cardiac events. Circulation 2003; 107:2571-2576.

54 Park R, Detrano R, Xiang M, Fu P, Ibrahim Y, LaBree L, Azen S: Combined use of computed tomography coronary calcium scores and Creactive protein levels in predicting cardiovascular events in nondiabetic individuals. Circulation 2002;106:2073-2077.

55 Wexler L, Brundage B, Crouse J, Detrano R, Fuster V, Maddahi J, Rumberger J, Stanford W, White R, Taubert K: Coronary artery calcification: Pathophysiology, epidemiology, imaging methods, and clinical implications. A statement for health professionals from the American Heart Association Writing Group. Circulation 1996;94:1175-1192.

56 Schmermund A, Erbel R: Unstable coronary plaque and its relation to coronary calcium. Circulation 2001;104:1682-1687.

57 Lee TC, O'Malley PG, Feuerstein I, Taylor AJ: The prevalence and severity of coronary artery calcification on coronary artery computed tomography in black and white subjects. J Am Coll Cardiol 2003;41:39-44.

58 Budoff MJ, Oudiz RJ, Zalace CP, Bakhsheshi H, Goldberg SL, French WJ, Rami TG, Brundage $\mathrm{BH}$ : Intravenous three-dimensional coronary angiography using contrast-enhanced electron-beam computed tomography. Am J Cardiol 1999;83:840-845.

59 Achenbach S, Moshage W, Ropers D, Nossen J, Daniel WG: Value of electron-beam computed tomography for the noninvasive detection of high-grade coronary artery stenoses and occlusions. N Engl J Med 1998;339:1964-1971.
60 Zarrabi AD, Dong Z, Cohen A, Litovsky S, Madjid M, Casscells W, Willerson JT, Naghavi M: A Novel liposomal encapsulated iohexol (Omnipaque) for detection of inflammation by computed tomography: A potential method for identification of vulnerable plaques; in: Imaging and Vulnerable Plaque. TCT 2002 [abstract].

61 Fayad ZA, Fuster V, Nikolaou K, Becker C: Computed tomography and magnetic resonance imaging for noninvasive coronary angiography and plaque imaging: Current and potential future concepts. Circulation 2002;106: 2026-2034.

62 Toussaint JF, LaMuraglia GM, Southern JF, Fuster V, Kantor HL: Magnetic resonance images lipid, fibrous, calcified, hemorrhagic, and thrombotic components of human atherosclerosis in vivo. Circulation 1996;94:932938.

63 Hatsukami TS, Ross R, Polissar NL, Yuan C: Visualization of fibrous cap thickness and rupture in human atherosclerotic carotid plaque in vivo with high-resolution magnetic resonance imaging. Circulation 2000;102:959-964.

64 Fayad ZA, Nahar T, Fallon JT, Goldman M, Aguinaldo JG, Badimon JJ, Shinnar M, Chesebro JH, Fuster V: In vivo magnetic resonance evaluation of atherosclerotic plaques in the human thoracic aorta: A comparison with transesophageal echocardiography. Circulation 2000;101:2503-2509.

65 Johnstone MT, Botnar RM, Perez AS, Stewart R, Quist WC, Hamilton JA, Manning WJ: In vivo magnetic resonance imaging of experimental thrombosis in a rabbit model. Arterioscler Thromb Vasc Biol 2001;21:1556-1560.

66 Fayad ZA, Fuster V, Fallon JT, Jayasundera T, Worthley SG, Helft G, Aguinaldo JG, Badimon JJ, Sharma SK: Noninvasive in vivo human coronary artery lumen and wall imaging using black-blood magnetic resonance imaging. Circulation 2000;102:506-510.

67 Worthley SG, Helft G, Fuster V, Zaman AG, Fayad ZA, Fallon JT, Badimon JJ: Serial in vivo MRI documents arterial remodeling in experimental atherosclerosis. Circulation 2000;101:586-589.

68 Corti R, Fayad ZA, Fuster V, Worthley SG, Helft G, Chesebro J, Mercuri M, Badimon JJ: Effects of lipid-lowering by simvastatin on human atherosclerotic lesions: A longitudinal study by high-resolution, noninvasive magnetic resonance imaging. Circulation 2001;104: 249-252.

69 Helft G, Worthley SG, Fuster V, Fayad ZA, Zaman AG, Corti R, Fallon JT, Badimon JJ: Progression and regression of atherosclerotic lesions: Monitoring with serial noninvasive magnetic resonance imaging. Circulation 2002; 105:993-998.

70 Zhao XQ, Yuan C, Hatsukami TS, Frechette EH, Kang XJ, Maravilla KR, Brown BG: Effects of prolonged intensive lipid-lowering therapy on the characteristics of carotid atherosclerotic plaques in vivo by MRI: A case-control study. Arterioscler Thromb Vasc Biol 2001;21: 1623-1629.
71 Yuan C, Kerwin WS, Ferguson MS, Polissar N, Zhang S, Cai J, Hatsukami TS: Contrast-enhanced high-resolution MRI for atherosclerotic carotid artery tissue characterization. J Magn Reson Imaging 2002; 15:62-67.

72 Flacke S, Fischer S, Scott MJ, Fuhrhop RJ, Allen JS, McLean M, Winter P, Sicard GA, Gaffney PJ, Wickline SA, Lanza GM: Novel MRI contrast agent for molecular imaging of fibrin: Implications for detecting vulnerable plaques. Circulation 2001;104:1280-1285.

73 Ruehm SG, Corot C, Vogt P, Kolb S, Debatin JF: Magnetic resonance imaging of atherosclerotic plaque with ultrasmall superparamagnetic particles of iron oxide in hyperlipidemic rabbits. Circulation 2001;103:415-422.

74 Kooi ME, Cappendijk VC, Cleutjens KB, Kessels AG, Kitslaar PJ, Borgers M, Frederik PM, Daemen MJ, van Engelshoven JM: Accumulation of ultrasmall superparamagnetic particles of iron oxide in human atherosclerotic plaques can be detected by in vivo magnetic resonance imaging. Circulation 2003; 107:2453-2438.

75 Choudhury RP, Fuster V, Badimon JJ, Fisher EA, Fayad ZA: MRI and characterization of atherosclerotic plaque: Emerging applications and molecular imaging. Arterioscler Thromb Vasc Biol 2002;22:1065-1074.

76 Worthley SG, Helft G, Fuster V, Fayad ZA, Rodriguez OJ, Zaman AG, Fallon JT, Badimon JJ: Noninvasive in vivo magnetic resonance imaging of experimental coronary artery lesions in a porcine model. Circulation 2000; 101:2956-2961.

77 Fayad ZA, Fuster V: The human high-risk plaque and its detection by magnetic resonance imaging. Am J Cardiol 2001;88:42E-45E.

78 Botnar RM, Kim WY, Bornert P, Stuber M, Spuentrup E, Manning WJ: 3D coronary vessel wall imaging utilizing a local inversion technique with spiral image acquisition. Magn Reson Med 2001;46:848-854.

79 Botnar RM, Stuber M, Kissinger KV, Manning WJ: Free-breathing 3D coronary MRA: The impact of 'isotropic' image resolution. J Magn Reson Imaging 2000;11:389-393.

80 Kim WY, Danias PG, Stuber M, Flamm SD, Plein S, Nagel E, Langerak SE, Weber OM, Pedersen EM, Schmidt M, Botnar RM, Manning WJ: Coronary magnetic resonance angiography for the detection of coronary stenoses. N Engl J Med 2001;345:1863-1869.

81 Zarrabi A, Gul K, Willerson JT, Casscells W, Naghavi M: Intravascular thermography: A novel approach for detection of vulnerable plaque. Curr Opin Cardiol 2002;17:656-662.

82 Casscells W, Hathorn B, David M, Krabach T, Vaughn WK, McAllister HA, Bearman G, Willerson JT: Thermal detection of cellular infiltrates in living atherosclerotic plaques: Possible implications for plaque rupture and thrombosis. Lancet 1996;347:1447-1451.

83 Naghavi M, John R, Naguib S, Siadaty MS, Grasu R, Kurian KC, van Winkle WB, Soller B, Litovsky S, Madjid M, Willerson JT, Casscells W: $\mathrm{pH}$ heterogeneity of human and rabbit atherosclerotic plaques: A new insight into detection of vulnerable plaque. Atherosclerosis $2002 ; 164: 27-35$. 
84 Stefanadis C, Diamantopoulos L, Vlachopoulos C, Tsiamis E, Dernellis J, Toutouzas K, Stefanadi E, Toutouzas P: Thermal heterogeneity within human atherosclerotic coronary arteries detected in vivo: A new method of detection by application of a special thermography catheter. Circulation 1999;99:1965-1971.

85 Stefanadis C, Diamantopoulos L, Dernellis J, Economou E, Tsiamis E, Toutouzas K, Vlachopoulos C, Toutouzas P: Heat production of atherosclerotic plaques and inflammation assessed by the acute-phase proteins in acute coronary syndromes. J Mol Cell Cardiol 2000;32:43-52.
86 Madjid M, Naghavi M, Malik BA, Litovsky S, Willerson JT, Casscells W: Thermal detection of vulnerable plaque. Am J Cardiol 2002;90: 36L-39L.

87 Stefanadis C, Toutouzas K, Tsiamis E, Stratos C, Vavuranakis M, Kallikazaros I, Panagiotakos D, Toutouzas P: Increased local temperature in human coronary atherosclerotic plaques: An independent predictor of clinical outcome in patients undergoing a percutaneous coronary intervention. J Am Coll Cardiol 2001; 37:1277-1283.

88 Stefanadis C, Toutouzas K, Vavuranakis M, Tsiamis E, Tousoulis D, Panagiotakos DB, Vaina S, Pitsavos C, Toutouzas P: Statin treatment is associated with reduced thermal heterogeneity in human atherosclerotic plaques. Eur Heart J 2002;23:1664-1669.
89 Tsimikas S: Noninvasive imaging of oxidized low-density lipoprotein in atherosclerotic plaques with tagged oxidation-specific antibodies. Am J Cardiol 2002;90:22L-27L.

90 Lindner JR: Detection of inflamed plaques with contrast ultrasound. Am J Cardiol 2002; 90:32L-35L.

91 Rudd JH, Warburton EA, Fryer TD, Jones HA, Clark JC, Antoun N, Johnstrom P, Davenport AP, Kirkpatrick PJ, Arch BN, Pickard JD, Weissberg PL: Imaging atherosclerotic plaque inflammation with $\left[{ }^{18} \mathrm{~F}\right]$-fluorodeoxyglucose positron emission tomography. Circulation 2002;105:2708-2711. 